\title{
POSTURA ESTRATÉGICA PARA INOVAÇÃO SUSTENTÁVEL E A SUA RELAÇÃO COM O ESTÁGIO DE INTERNACIONALIZAÇÃO EM EMPRESAS INDUSTRIAIS BRASILEIRAS
}

\author{
STRATEGIC POSTURE TO SUSTAINABLE INNOVATION AND ITS RELATIONSHIP WITH \\ INTERNATIONALIZATION STAGE IN BRAZILIAN INDUSTRIAL COMPANIES
}

\author{
JORDANA MARQUES KNEIPP \\ Professora na Universidade Federal de Santa Maria - UFSM \\ Doutora em Administração
}

E-mail: jordana.kneipp@ufsm.br / Orcid: https://orcid.org/0000-0001-6982-994X

Endereço: Av. Roraima no 1000, prédio 74c, sala 4204, Cidade Universitária, Bairro Camobi, Santa Maria (RS) - CEP: 97.105-900

\section{CLANDIA MAFFINI GOMES}

Professora na Universidade Federal de Santa Maria - UFSM

Doutora em Administração

E-mail: clandiamaffinigomes@hotmail.com / Orcid: https://orcid.org/0000-0002-4093-5906

\section{KAMILA FRIZZO}

Doutoranda em Administração pela Universidade Federal de Santa Maria - UFSM

E-mail: kamilafrizzo@gmail.com / Orcid: https://orcid.org/0000-0002-0858-7614

\section{GABRIELA ROSSATO}

Universidade Federal de Santa Maria

Mestranda em Administração pela Universidade Federal de Santa Maria - UFSM

E-mail: gabi.rossato@hotmail.com / Orcid: https://orcid.org/0000-0002-9407-3213

\section{LEISLY CENTENARO}

Graduada em Administração pela Universidade Federal de Santa Maria - UFSM

E-mail: leisly_wcenter@hotmail.com / Orcid: https://orcid.org/0000-0001-9216-5440

\section{RESUMO}

Os fatores condicionantes do mundo globalizado criam novas exigências e oportunidades em relação ao desenvolvimento de um modelo de gestão para as organizações que contemple as premissas da sustentabilidade, o que pressupõe investimentos substanciais em inovação. Este estudo teve como objetivo analisar a relação da postura estratégica para a inovação sustentável com o estágio de internacionalização de empresas industriais brasileiras. O estudo caracterizou-se como quantitativo e compreendeu a realização de uma pesquisa survey com empresas industriais brasileiras. Os resultados permitiram observar que as empresas internacionalizadas possuem maior tendência há adotarem uma estratégia pró-ativa em prol da inovação sustentável. A partir do exposto, é possível depreender que a postura estratégica para a inovação sustentável e a internacionalização representam questões importantes no contexto das empresas analisadas.

Palavras-chave: Postura estratégica. Inovação sustentável. Internacionalização. 


\begin{abstract}
The conditioning factors of the globalized world create new requirements and opportunities for the development of a management model for organizations that includes the premises of sustainability, which requires substantial investments in innovation. This study aimed to analyze the relationship of the strategic posture to sustainable innovation to the stage of internationalization of Brazilian industrial companies. The study was characterized as quantitative and a survey research with Brazilian industrial companies was conducted. Results showed that the internationalized companies have a higher trend for adopting a proactive strategy for sustainable innovation. From the foregoing, it is possible to conclude that the strategic posture for sustainable innovation and internationalization are important issues in the context of the companies analyzed.
\end{abstract}

Keywords: Strategic posture. Sustainable innovation. Internationalization.

\title{
1 INTRODUÇÃO
}

Cada vez mais as empresas vêm percebendo a importância da adoção de uma gestão estratégica da inovação sustentável a fim de atender os condicionantes do mundo globalizado e obter um desempenho empresarial superior. A legislação e a própria sociedade vêm exigindo das organizações que a inovação em produtos, serviços, processos e modelos de negócios seja acompanhada pela responsabilidade com o desenvolvimento sustentável a fim de minimizar possíveis impactos negativos dos processos industriais.

Lacy et al. (2010) ressaltam que práticas de gestão e produtos sustentáveis estão abrindo novos mercados e fontes de demanda, trazendo a necessidade de novos modelos de negócios e fontes de inovação que alterem as estruturas de custos da indústria, de forma que a sustentabilidade permeie desde a estratégia corporativa até todas as operações da empresa.

A gestão da inovação sustentável tem sido associada em alguns estudos com a atuação internacional das empresas. Autores sugerem que é fundamental estimular a inovação sustentável para ganhar acesso a mercados internacionais, sendo muitas vezes um requisito básico para melhorar os negócios internacionais (LOPEZ-VALEIRAS, GOMEZ-CONDE; NARANJO-GIL, 2015; ADA, KAZANCOGLU; SAGNAK, 2013).

Tendo em vista que a adoção de uma gestão estratégica da inovação sustentável pode estar associada com a atuação internacional das empresas podendo ser uma propulsora na abertura de mercados no exterior, o presente estudo busca entender: Qual a relação da postura estratégica para a inovação sustentável com o estágio de internacionalização de empresas industriais brasileiras? Desse modo, o estudo busca analisar a relação da postura estratégica para a inovação sustentável com o estágio de internacionalização de empresas industriais brasileiras.

O presente estudo, ao tratar das temáticas da gestão estratégica da inovação sustentável e da atuação internacional pode impulsionar a adoção de um comportamento empresarial que integre os objetivos da inovação sustentável de forma estratégica e sistêmica e contribua para uma maior atuação internacional das empresas brasileiras.

Este trabalho está estruturado em quatro seções além desta introdução. A segunda apresenta o aporte teórico, a terceira seção trata dos procedimentos metodológicos do estudo. Logo após, é apresentada a análise e discussão dos resultados e por fim as considerações finais. 


\section{POSTURA ESTRATÉGICA PARA A INOVAÇÃO SUSTENTÁVEL E A SUA RELAÇÃO COM A INTERNACIONALIZAÇÃO}

A adoção de uma estratégia de inovação sustentável pode propiciar ganhos em competitividade para as organizações. Nesse sentido, Bossink (2002) destaca que as mudanças políticas, econômicas, sociais e nas relações com os stakeholders têm estimulado as empresas a desenvolverem estratégias de inovação para a sustentabilidade.

Para Daroit e Nascimento (2004), a inovação está comumente associada ao enfoque econômico, sendo tratada apenas como forma de obtenção de lucros extras pelas empresas, por meio de vantagens competitivas decorrentes da produção de novos produtos ou processos que agregam valor para o cliente. No entanto, estes autores enfatizam que é preciso uma maior compreensão por parte das organizações sobre o papel da inovação com relação a seus efeitos sobre a sociedade e o meio ambiente.

Na visão de Charter e Clark (2007), não existe um conceito único estabelecido para a inovação sustentável, refletindo a dificuldade no que se refere às definições de sustentabilidade e de desenvolvimento sustentável. Contudo, os autores destacam que, apesar dessa dificuldade conceitual, há um reconhecimento emergente de que a inovação sustentável está relacionada ao empreendedorismo e a novos conceitos, tecnologias, produtos e serviços, e ainda à adoção de novos processos e de sistemas sociais.

Charter e Clark (2007) ressaltam que, embora os termos "inovação sustentável" e "eco inovação" sejam frequentemente usados como sinônimos, a eco inovação somente aborda as dimensões ambiental e econômica, enquanto a inovação sustentável, além destas dimensões, engloba os aspectos éticos e sociais. Complementando, para Boons et al. (2013), a inovação sustentável vai além da ecoinovação, pois inclui objetivos sociais e está mais claramente relacionada ao processo holístico e de longo prazo do desenvolvimento sustentável.

A estratégia de inovação sustentável pode ser definida como a criação de algo novo que propicia a melhoria no desempenho nas três dimensões do desenvolvimento sustentável: social, ambiental e econômica. Tais melhorias não se restringem a mudanças tecnológicas, podendo estar relacionadas a modificações em processos, práticas operacionais, modelos de negócios, pensamento e sistemas empresariais (SZEKELY; STREBEL, 2012).

A estratégia de inovação para a sustentabilidade pode ocorrer de forma incremental ou radical. Na visão de Szekely e Strebel (2012), o desenvolvimento de novos produtos, serviços e processos internos integrando aspectos ambientais, sociais e econômicos tem ocorrido em grande parte de forma incremental e relaciona-se principalmente a questões ambientais e econômicas, com menor ênfase nos aspectos sociais.

Uma estratégia de inovação radical para a sustentabilidade ocorre por meio de uma mudança sistêmica no pensamento da sociedade. A transformação das cadeias de suprimentos empresariais a partir da incorporação da sustentabilidade exige uma visão sistêmica dos impactos de produtos, serviços, processos e operações, incluindo questões sociais, tais como condições de trabalho, saúde e equidade humana; questões ambientais, como compra de matérias-primas, processos de fabricação e descarte; e questões econômicas, como competitividade e participação no mercado (SZEKELY; STREBEL, 2012).

Para Placet, Anderson e Flower (2005), melhorias incrementais em produtos e processos pouco provavelmente resultarão em progressos no que tange ao desenvolvimento sustentável. Os autores defendem que inovações radicais devem ser consideradas na estratégia e nas operações empresariais, uma vez que são necessárias para o desenvolvimento de novos processos e de novos produtos que sejam menos agressivos ao meio ambiente e que 
contemplem aspectos sociais e ambientais.

Nidumolu, Prahalad e Rangaswani (2009), ao estudarem iniciativas sustentáveis de grandes organizações, observam que o sucesso está relacionado ao fato de a sustentabilidade ser vislumbrada como uma nova fronteira da inovação. Para os autores, as empresas bemsucedidas equacionam a sustentabilidade com a inovação e, desse modo, ganham vantagem competitiva, tendo em vista que redesenham produtos, tecnologias, processos e modelos de negócios e ainda reduzem custos, pois acabam utilizando menos insumos, e também os novos processos e produtos geram receitas adicionais ou permitem a criação de novos negócios.

Ainda os autores destacam que o compromisso empresarial com a sustentabilidade envolve cinco estágios distintos de inovação, a saber: 1) visualização da conformidade com a legislação como oportunidade, 2) desenvolvimento de cadeias de valor sustentáveis, 3) desenvolvimento de produtos e serviços sustentáveis, 4) desenvolvimento de novos modelos de negócios e 5) criação de plataformas de práticas de última geração.

O Quando 1 apresenta os desafios da sustentabilidade, as competências e oportunidades para a inovação.

Quadro 1 - Estágios de estratégia de inovação sustentável

\begin{tabular}{|c|c|c|c|}
\hline Estágios & Desafio Central & Competências Necessárias & Oportunidades de inovação \\
\hline $\begin{array}{l}\text { 1) Visualizando } \\
\text { a conformidade } \\
\text { com a legislação } \\
\text { como } \\
\text { oportunidade }\end{array}$ & $\begin{array}{l}\text { Garantir que o } \\
\text { cumprimento das } \\
\text { normas se torne } \\
\text { uma } \\
\text { oportunidade } \\
\text { para a inovação. }\end{array}$ & $\begin{array}{l}\text { - Capacidade para se antecipar e } \\
\text { moldar regulamentos. } \\
\text { - Habilidade em trabalhar com } \\
\text { outras empresas, incluindo rivais, } \\
\text { para implementar soluções } \\
\text { criativas. }\end{array}$ & $\begin{array}{l}\text { Utilizar o cumprimento das } \\
\text { normas para induzir a } \\
\text { empresa e seus parceiros a } \\
\text { experimentar tecnologias, } \\
\text { materiais e processos } \\
\text { sustentáveis. }\end{array}$ \\
\hline $\begin{array}{l}\text { 2) Tornando as } \\
\text { cadeias de valor } \\
\text { sustentáveis }\end{array}$ & $\begin{array}{l}\text { Aumentar a } \\
\text { eficiência em toda } \\
\text { a cadeia de valor. }\end{array}$ & $\begin{array}{l}\text { - Especialização em técnicas como a } \\
\text { gestão de carbono e avaliação do } \\
\text { ciclo de vida. } \\
\text { - Capacidade de redesenhar as } \\
\text { operações a fim de usar menos } \\
\text { energia e água, produzir menos } \\
\text { emissões e gerar menos resíduos; } \\
\text { - Capacidade de assegurar que os } \\
\text { fornecedores e varejistas tornem } \\
\text { suas operações sustentáveis. }\end{array}$ & $\begin{array}{l}\text { - Desenvolvimento de fontes } \\
\text { sustentáveis de matérias- } \\
\text { primas e componentes; } \\
\text { - Aumento do uso de fontes de } \\
\text { energia limpa, como a energia } \\
\text { eólica er solar. } \\
\text { - Encontrar usos inovadores } \\
\text { para os produtos devolvidos. }\end{array}$ \\
\hline $\begin{array}{l}\text { 3) } \\
\text { Desenvolvendo } \\
\text { produtos e } \\
\text { serviços } \\
\text { sustentáveis }\end{array}$ & $\begin{array}{l}\text { Desenvolver } \\
\text { produtos e } \\
\text { serviços } \\
\text { sustentáveis ou } \\
\text { redesenhar os já } \\
\text { existentes para } \\
\text { que se tornem } \\
\text { sustentáveis. }\end{array}$ & $\begin{array}{l}\text { - Habilidade em conhecer os } \\
\text { produtos ou serviços que são mais } \\
\text { agressivos ao meio ambiente. } \\
\text { - Capacidade de suportar } \\
\text { publicamente produtos e serviços } \\
\text { sustentáveis e não ser considerada } \\
\text { "greenwashing". } \\
\text { - Conhecimento gerencial para } \\
\text { dimensionar as fontes de materiais } \\
\text { verdes e a fabricação de produtos. }\end{array}$ & $\begin{array}{lr}\text { Aplicação de técnicas como } \\
\text { biomimetismo } & \text { no } \\
\text { desenvolvimento } & \text { de } \\
\text { produtos. } & \\
\text { - Desenvolvimento de } \\
\text { embalagens compactas e } \\
\text { ecoeficientes. }\end{array}$ \\
\hline $\begin{array}{l}\text { 4) } \\
\text { Desenvolvendo } \\
\text { novos modelos } \\
\text { de negócios }\end{array}$ & $\begin{array}{l}\text { Encontrar novas } \\
\text { formas de entrega } \\
\text { e captação de } \\
\text { valor, que irão } \\
\text { mudar a base de } \\
\text { competição. }\end{array}$ & $\begin{array}{l}\text { - Capacidade de compreender os } \\
\text { desejos dos consumidores e } \\
\text { descobrir diferentes maneiras de } \\
\text { atender a essas demandas. } \\
\text { - Capacidade de compreender como } \\
\text { os parceiros podem aumentar o } \\
\text { valor de oferta. }\end{array}$ & $\begin{array}{l}\text { - Desenvolvimento de novas } \\
\text { tecnologias de entrega a fim } \\
\text { de mudar significativamente } \\
\text { as relações da cadeia de valor. } \\
\text { - Criação de modelos } \\
\text { monetários relacionados a } \\
\text { serviços ao invés de produtos. } \\
\text { - Elaboração de modelos de } \\
\text { negócios que combinem }\end{array}$ \\
\hline
\end{tabular}




\begin{tabular}{|c|c|c|c|}
\hline Estágios & Desafio Central & Competências Necessárias & Oportunidades de inovação \\
\hline & & & $\begin{array}{l}\text { infraestruturas digitais e } \\
\text { físicas. }\end{array}$ \\
\hline $\begin{array}{l}\text { 5) Criando } \\
\text { plataformas de } \\
\text { práticas de } \\
\text { última geração }\end{array}$ & $\begin{array}{l}\text { Questionar, por } \\
\text { meio da lente de } \\
\text { sustentabilidade, } \\
\text { a lógica } \\
\text { dominante dos } \\
\text { negócios. }\end{array}$ & $\begin{array}{l}\text { - Conhecimento dos impactos dos } \\
\text { recursos renováveis e não } \\
\text { renováveis nos ecossistemas. } \\
\text { - Experiência para sintetizar } \\
\text { modelos de negócios, tecnologias e } \\
\text { regulamentos em diferentes } \\
\text { indústrias. }\end{array}$ & $\begin{array}{l}\text { - Construção de plataformas } \\
\text { de negócios que permitam a } \\
\text { clientes e fornecedores } \\
\text { gerenciar a energia de } \\
\text { maneiras radicalmente } \\
\text { diferentes. } \\
\text { - Desenvolvimento de } \\
\text { produtos que não necessitem } \\
\text { de adição de água, tais como } \\
\text { produtos de limpeza. } \\
\text { - Concepção de tecnologias } \\
\text { que permitam às indústrias } \\
\text { utilizarem a energia produzida } \\
\text { como um subproduto. }\end{array}$ \\
\hline
\end{tabular}

Fonte: Nidumolu, Prahalad e Rangaswani (2009, p. 6-7).

De acordo com os elementos apresentados no Quadro 1, é possível perceber que, na concepção de Nidumolu, Prahalad e Rangaswani (2009), as iniciativas de sustentabilidade empresarial estão associadas a oportunidades de inovação e possuem um aspecto evolutivo, tendo em vista que perpassam por cinco estágios, visando atender, em um primeiro momento, aos aspectos legais, passando pelo envolvimento da stakeholders, pelo desenvolvimento de novos produtos e serviços e de novos modelos de negócios, até alcançar o estágio mais complexo, que se refere à criação de práticas de última geração.

Tendo como base as tipologias de estratégica de inovação e de sustentabilidade apresentadas e os objetivos do presente estudo, propõe-se uma taxonomia de inovação sustentável fundamentada nas propostas de Eiriz, Faria e Barbosa (2013) e de Schaltegger, Lüdeke-Freund e Hansen (2012), conforme apresentado na Figura 1.

Figura 1 - Proposta de tipologia estratégica de inovação sustentável

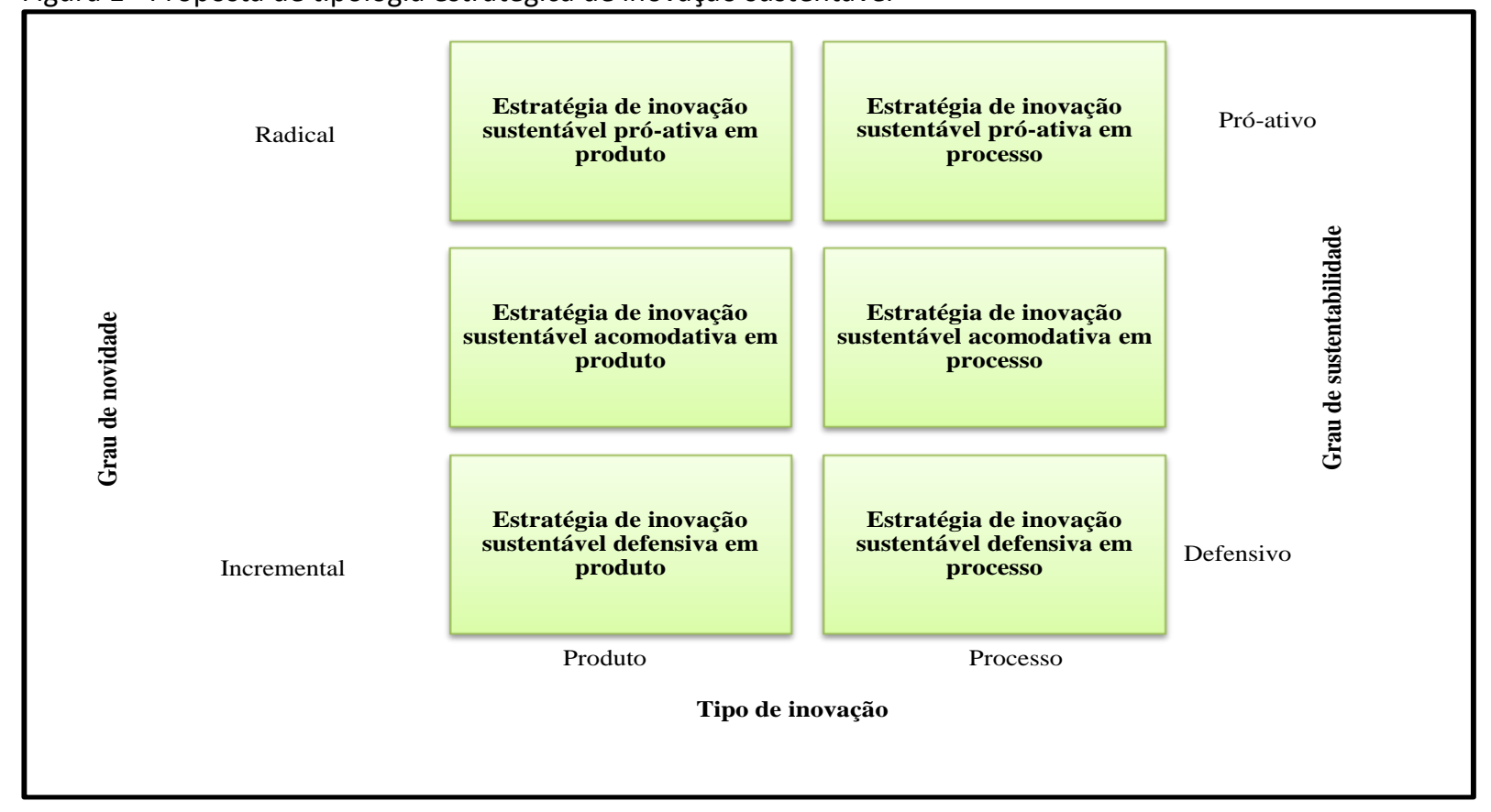

Fonte: baseado em Schaltegger, Lüdeke-Freund e Hansen (2012) e Eiriz, Faria e Barbosa (2013, p.104). 
A tipologia estratégica de inovação sustentável propõe a classificação em termos do tipo de inovação (produto e processo), do seu grau de novidade (incremental e radical) e do seu nível de sustentabilidade (defensivo, acomodativo e pró-ativo), sendo identificadas seis categorias estratégicas: I) pró-ativa em produto; II) pró-ativa em processo; III) acomodativa em produto; IV) acomodativa em processo; V) defensiva em produto; VI) defensiva em processo.

A estratégia para a inovação sustentável classificada como pró-ativa em produto está relacionada a níveis de inovação radical e representa a integração dos objetivos sociais e ambientais em produtos da empresa. A estratégia pró-ativa em processo visa integrar a sustentabilidade nos processos empresariais por meio da inovação radical. As empresas que operam priorizando estas estratégias integram a sustentabilidade à lógica de geração de receita e ao negócio principal da empresa e buscam a liderança por meio do seu desempenho sustentável, que está diretamente relacionado com as suas ações inovadoras.

As estratégias classificadas como acomodativas podem estar relacionadas a produtos e/ou processos e apresentam um grau de novidade intermediário, ou seja, integram os objetivos ambientais ou sociais em parte dos produtos e/ou serviços e processos do negócio. No entanto, esta estratégia não está relacionada com a lógica de geração de receita e ao negócio principal da empresa.

A postura estratégica defensiva caracteriza-se como reativa, está associada a níveis incrementais de inovação e pode ter um enfoque maior em produto ou processo, visando primordialmente atender aos requisitos legais e/ou pressões externas a fim de evitar custos. Tais estratégias não estão relacionadas à obtenção de vantagem competitiva por meio do desempenho sustentável.

Convém destacar que as seis categorias não são mutuamente excludentes, podendo a empresa desenvolver mais de uma opção ao mesmo tempo, de modo que, no estudo, buscase identificar a tipologia predominante nas empresas analisadas.

A postura estratégica para a inovação sustentável irá direcionar as ações empresariais, por meio do desenvolvimento de novos produtos, serviços, tecnologias e processos que integrem elementos econômicos, sociais e ambientais, desse modo, o próximo tópico trata das práticas de inovação sustentável.

A gestão da inovação sustentável também tem sido associada em alguns estudos com a atuação internacional das empresas. Alguns autores sugerem que é fundamental estimular a inovação sustentável para ganhar acesso a mercados internacionais, sendo muitas vezes um requisito básico para melhorar os negócios internacionais (LOPEZ-VALEIRAS, GOMEZ-CONDE; NARANJO-GIL, 2015; ADA, KAZANCOGLU; SAGNAK, 2013).

Hrdlicka e Neiman (2012) em seu estudo abordam conjuntamente os temas da sustentabilidade e da internacionalização, em virtude da sua relevância no contexto brasileiro, em face a evolução positiva do desempenho das exportações brasileiras nos últimos anos e as preocupações crescentes para a sustentabilidade do planeta no âmbito empresarial. Em pesquisa empírica realizada junto a cinquenta e nove empresas brasileiras constataram que a gestão ambiental corporativa integrada com P\&D e promoção de marketing fornece uma relação importante com o desempenho das exportações.

Christmann e Taylor (2001) colocam que embora haja uma vertente de críticos que considera a globalização prejudicial ao meio ambiente, em virtude de promover a instalação de indústrias poluentes em países com poucas normas ambientais, ela também pode propiciar efeitos ambientais positivos considerando que os laços globais aumentam as pressões 
institucionais para que as empresas adotem sistemas de gestão ambiental, além dos requisitos de regulamentações governamentais. Além disso, as certificações internacionais são um mecanismo de autorregulação essencial para desenvolver os princípios de sustentabilidade e os seus efeitos influenciam no desempenho da empresa em relação a questão abordada pela norma. (CHRISTMANN; TAYLOR, 2001)

A partir das temáticas apresentadas, busca-se analisar a relação da postura estratégica para a inovação sustentável com o estágio de internacionalização de empresas industriais brasileiras. Assim, a seguir é apresentado o método para desenvolvimento do estudo.

\section{MÉTODO DO ESTUDO}

A pesquisa de natureza quantitativa foi delineada por meio de um survey com empresas industriais brasileiras que apresentaram investimentos em inovação. $O$ modelo conceitual adotado no estudo aborda de forma conjunta as temáticas de postura estratégica para a inovação sustentável e internacionalização, conforme apresentado na Figura 2.

Figura 2 - Modelo conceitual

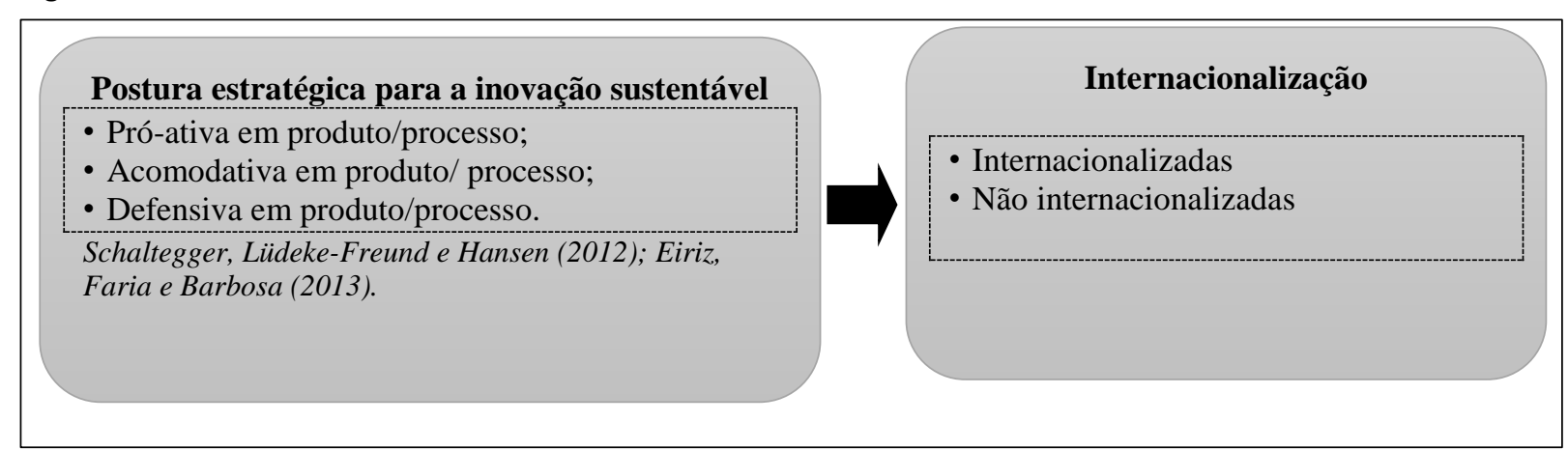

Fonte: elaborado a partir de Schaltegger, Lüdeke-Freund e Hansen (2012); Eiriz, Faria e Barbosa (2013).

A postura estratégica para a inovação sustentável baseou-se nos estudos de Schaltegger, Lüdeke-Freund e Hansen (2012) e Eiriz, Faria e Barbosa (2013), e contemplou o tipo de inovação (produto e processo), o grau de novidade (incremental e radical) e o nível de sustentabilidade (defensivo, acomodativo e pró-ativo). De modo que se propõe uma tipologia de acordo com as seguintes categorias: I) pró-ativa em produto; II) pró-ativa em processo; III) acomodativa em produto; IV) acomodativa em processo; V) defensiva em produto; VI) defensiva em processo.

Tendo como base o estágio de internacionalização as empresas foram divididas em internacionalizadas e não internacionalizadas: 1 ) Não internacionalizadas: estágio nulo (não atua no mercado externo), estágio muito baixo (atua muito pouco no mercado externo), estágio baixo (atua pouco no mercado externo); 2) Internacionalizadas: estágio médio (atua com regularidade no mercado externo), estágio alto (alta atuação no mercado externo), estágio muito alto (atuação total no mercado externo).

Para a coleta de dados elaborou-se um questionário estruturado baseado na revisão da literatura. O questionário compõe-se de perguntas fechadas e utilizou uma escala intervalar, na qual os respondentes assinalaram o grau (nota) que melhor traduzia a sua concordância em relação às ações adotadas pela empresa no intervalo entre 1 (menor grau de concordância) e 5 (máxima concordância). O instrumento de coleta de dados foi validado por especialistas das áreas de inovação e sustentabilidade. Seguindo as sugestões dos 
especialistas, o questionário foi aperfeiçoado e, na sequência, foi realizado um pré-teste com três empresas a fim de verificar a sua adequação e as dificuldades encontradas no preenchimento. Depois de realizados os ajustes sugeridos pelas empresas na etapa de préteste, procedeu-se o início da coleta de dados.

A população-alvo do estudo constitui-se de 256 empresas vinculadas à Associação Nacional de Pesquisa e Desenvolvimento das Empresas Inovadoras (ANPEI) e participantes da Feira de subcontratação e inovação industrial da América Latina (MERCOPAR) no ano de 2015. Os questionários foram enviados por meio de plataforma online para todas as empresas objeto do estudo no período de setembro de 2015 a janeiro de 2016. Obteve-se um retorno de 51 questionários, representando 19,92\% da população pesquisada. Apesar de o índice de retorno não ser considerado elevado, os resultados obtidos permitem a análise específica das características e comportamentos das empresas estudadas. As evidências encontradas não poderão ser extrapoladas para o universo de pesquisa considerado.

Os dados coletados foram tabulados com o auxílio dos softwares Microsoft Excel e Statistical Package for the Social Sciences - SPSS e analisados por meio de estatística descritiva.

\section{ANÁLISE E DISCUSSÃO DOS RESULTADOS}

Para fins deste estudo as empresas participantes da pesquisa foram divididas em não internacionalizadas e internacionalizadas considerando o estágio de internacionalização em que as empresas se encontram.

A Tabela 1 apresenta o estágio de internacionalização das empresas pesquisadas.

Tabela 1 - Estágio de internacionalização

\begin{tabular}{l|c|c}
\multicolumn{1}{c}{ Estágio de internacionalização } & Frequência & $\%$ \\
\hline Estágio nulo (Não atua no mercado externo) & 21 & 41,2 \\
Estágio muito baixo (Atua muito pouco no mercado externo) & 9 & 17,6 \\
Estágio baixo (Atua pouco no mercado externo) & 6 & 11,8 \\
Estágio médio (Atua com regularidade no mercado externo) & 6 & 11,8 \\
Estágio alto (Alta atuação no mercado externo) & 7 & 13,7 \\
Estágio muito alto (Atuação total no mercado externo) & 2 & 3,9 \\
\hline Total & $\mathbf{5 1}$ & $\mathbf{1 0 0 , 0}$ \\
\hline
\end{tabular}

Fonte: dados da pesquisa.

A maioria das empresas não atua ou atua muito pouco no mercado externo, o que denota um baixo grau de internacionalização nas organizações estudadas, o que pode ser decorrente do fato de que, na amostra, há um predomínio de pequenas e microempresas que estão mais restritas à atuação no mercado interno dependendo do setor em que atuam.

$\mathrm{Na}$ Tabela 2 é apresentada a classificação das empresas quanto a internacionalização.

Tabela 2 - Classificação das empresas quanto a internacionalização

\begin{tabular}{l|c|c}
\multicolumn{1}{c|}{ Internacionalização } & Frequência & \% \\
\hline Não internacionalizadas & 36 & 70,6 \\
Internacionalizadas & 15 & $\mathbf{2 9 , 4}$ \\
\hline Total & $\mathbf{5 1}$ & $\mathbf{1 0 0 , 0}$ \\
\hline Fonte: dados da pesquisa.
\end{tabular}

Fonte: dados da pesquisa.

Para fins deste estudo foram consideradas internacionalizadas as empresas com médio, alto e muito alto estágio de internacionalização. 
A caracterização das empresas pesquisadas é analisada a partir da verificação das frequências observadas em relação à: tempo de existência da empresa, ramo de atuação, número de empregados e receita operacional bruta da empresa em 2014.

O tempo de existência das empresas pesquisadas é apresentado na Tabela 3.

Tabela 3 - Tempo de existência da empresa (anos)

\begin{tabular}{lcc}
\hline & Internacionalizada & Não internacionalizada \\
\hline Média & 43,97 anos & 24,00 anos \\
Mediana & 35 anos & 17,50 anos \\
Desvio-padrão & 37,41 & 22,83 \\
Coeficiente de variação & $85,08 \%$ & $95,12 \%$ \\
Tempo mínimo & 5,6 anos & 1,30 anos \\
Tempo máximo & 116 anos & 100 anos \\
\hline \multicolumn{1}{c}{ Total de empresas } & $\mathbf{1 5}$ & $\mathbf{3 6}$
\end{tabular}

Fonte: dados da pesquisa.

Os dados da pesquisa evidenciam que o tempo médio de existência das empresas pesquisadas é de 30 anos, sendo que a empresa mais antiga do setor possui 116 anos e a mais nova possui 1,3 anos. O tempo médio de existência das empresas é superior entre as empresas internacionalizadas, o que leva a supor que o nível de maturidade, de experiência e de atuação no mercado possa contribuir para o processo de internacionalização. na Tabela 4.

Os dados referentes ao ramo de atuação das empresas pesquisadas são apresentados Tabela 4-Ramo de atuação

\begin{tabular}{|c|c|c|c|c|}
\hline \multirow[b]{2}{*}{ Ramo de atuação } & \multicolumn{2}{|c|}{ Internacionalizada } & \multicolumn{2}{|c|}{ Não Internacionalizada } \\
\hline & Frequência & $\%$ & Frequência & $\%$ \\
\hline Agrícola/ Agroindustrial & 0 & , 0\% & 3 & $5,9 \%$ \\
\hline Automação Industrial & 1 & $2,0 \%$ & 2 & $3,9 \%$ \\
\hline Borracha & 0 & ,0\% & 1 & $2,0 \%$ \\
\hline Energia & 0 &, $0 \%$ & 2 & $3,9 \%$ \\
\hline Engenharia & 0 &, $0 \%$ & 2 & $3,9 \%$ \\
\hline Tecnológico & 3 & $5,9 \%$ & 8 & $15,7 \%$ \\
\hline Máquinas e Equipamentos & 4 & $7,8 \%$ & 7 & $13,7 \%$ \\
\hline Farmacêutico & 0 &, $0 \%$ & 1 & $2,0 \%$ \\
\hline Químico & 3 & $5,9 \%$ & 2 & $3,9 \%$ \\
\hline Óleo e Gás & 0 & ,0\% & 1 & $2,0 \%$ \\
\hline Produção papel & 1 & $2,0 \%$ & 0 &, $0 \%$ \\
\hline Saúde e Educação & 1 & $2,0 \%$ & 1 & $2,0 \%$ \\
\hline Tabaco & 1 & $2,0 \%$ & 0 & ,0\% \\
\hline Outros & 1 & $2,0 \%$ & 6 & $11,8 \%$ \\
\hline Total & 15 & 29,4 & 36 & 70,6 \\
\hline
\end{tabular}

Fonte: dados da pesquisa.

Percebe-se, a partir dos dados analisados, que o ramo de atuação das empresas internacionalizadas, concentra-se principalmente nas indústrias de máquinas e equipamentos, tecnológica e química.

O número de empregados e a receita operacional bruta do ano de 2014 são apresentados nas Tabelas 5 e 6, respectivamente. 
Tabela 5 - Número de funcionários

\begin{tabular}{ccccc}
\hline & Internacionalizada & \multicolumn{2}{c}{ Não Internacionalizada } \\
\hline Número de funcionários & Frequência & $\mathbf{\%}$ & Frequência & \% \\
\hline Até 19 empregados (microempresa) & 0 & 0,0 & 14 & 27,5 \\
De 20 a 99 empregados (pequena empresa) & 5 & 9,8 & 11 & 21,6 \\
De 100 a 499 empregados (média empresa) & 5 & 9,8 & 6 & 11,8 \\
Acima de 499 empregados (grande empresa) & 5 & 9,8 & 5 & 9,8 \\
\hline Total & $\mathbf{1 5}$ & $\mathbf{2 9 , 4}$ & $\mathbf{3 6}$ & $\mathbf{7 0 , 6}$ \\
\hline
\end{tabular}

Fonte: dados da pesquisa.

As empresas pesquisadas foram classificadas de acordo com o número de funcionários, conforme critério adotado pela classificação do SEBRAE (2004). Desse modo, é possível perceber, a partir dos dados analisados, entre as empresas internacionalizadas, que a maior parte delas é de pequeno, médio e grande porte e, no que se refere as empresas não internacionalizadas, a maioria classifica-se como microempresas. A receita operacional bruta das empresas pesquisadas é apresentada na Tabela 6.

Tabela 6 - Receita operacional bruta anual (ROB)

\begin{tabular}{|c|c|c|c|c|}
\hline \multirow[b]{2}{*}{ Receita operacional bruta } & \multicolumn{2}{|c|}{ Internacionalizada } & \multicolumn{2}{|c|}{ Não Internacionalizada } \\
\hline & Frequência & $\%$ & Frequência & $\%$ \\
\hline Até R\$̦ 2,4 milhões (microempresa) & 0 & 0,0 & 16 & 31,37 \\
\hline Acima de $\mathrm{R} \$ 2,4$ milhões até $\mathrm{R} \$ 16$ milhões & 0 & 0,0 & 11 & 21,57 \\
\hline Acima de $\mathrm{R} \$ 16$ milhões até $\mathrm{R} \$ 90$ milhões & 10 & 19,60 & 3 & 5,88 \\
\hline Acima de $R \$ 90$ milhões até $R \$ 300$ milhões & 0 & 0,0 & 1 & 1,96 \\
\hline Acima de 300 milhões (grande empresa) & 5 & 9,80 & 4 & 7,84 \\
\hline Não resposta & & & 1 & 1,96 \\
\hline Total & 15 & 29,4 & 36 & 70,6 \\
\hline
\end{tabular}

Fonte: dados da pesquisa.

É possível perceber, a partir dos dados analisados, que entre as empresas internacionalizadas, a maior parte das empresas apresenta receita operacional bruta na faixa acima de $\mathrm{R} \$ 16$ milhões até $\mathrm{R} \$ 90$ milhões e, entre as não internacionalizadas, a maior parte das empresas apresenta receita operacional bruta na faixa até $\mathrm{R} \$ 2,4$ milhões. Desse modo, é possível perceber, a partir dos dados analisados, que as empresas internacionalizadas são de maior porte quando comparadas as não internacionalizadas considerando o número de funcionários e a receita operacional bruta.

Na Tabela 7, é apresentado o tipo de inovação predominante introduzido pelas empresas nos últimos cinco anos.

Tabela 7 - Introdução no mercado de inovação nos últimos cinco anos

\begin{tabular}{lcccc}
\hline & \multicolumn{2}{c}{ Internacionalizada } & \multicolumn{2}{c}{ Não internacionalizada } \\
\hline Introdução no mercado de inovação & Frequência & $\mathbf{\%}$ & Frequência & $\mathbf{\%}$ \\
\hline Inovação em produto e em & 3 & 5,9 & 6 & 11,8 \\
Inovação em produto & 1 & 2,0 & 7 & 13,7 \\
Inovação em processo & 11 & 21,6 & 19 & 37,3 \\
Não se aplica & 0 & 0,0 & 4 & 7,8 \\
\hline Total & $\mathbf{1 5}$ & $\mathbf{2 9 , 4}$ & $\mathbf{3 6}$ & $\mathbf{7 0 , 6}$ \\
\hline
\end{tabular}

Fonte: dados da pesquisa.

Os dados sugerem que tanto as empresas internacionalizadas como as não internacionalizadas introduziram no mercado, nos últimos cinco anos, predominantemente, 
inovações em produto e em processo, evidenciando que a inovação em produto está atrelada a processo, o que pode contribuir para a obtenção de um desempenho empresarial superior.

A Tabela 8 apresenta a responsabilidade principal pela atividade de inovação.

Tabela 8 - Responsabilidade principal pela atividade de inovação

\begin{tabular}{lccccc}
\hline \multicolumn{1}{c}{ Responsabilidade principal pela atividade de inovação } & Internacionalizada & \multicolumn{2}{c}{ Não internacionalizada } \\
\hline A empresa é a única responsável pela atividade de inovação & 4 & 4,82 & 25 & 30,12 \\
A empresa inova em cooperação com outras empresas & 9 & 10,84 & 8 & 9,64 \\
A empresa inova em cooperação com institutos & 9 & 10,84 & 9 & 10,84 \\
A empresa inova em cooperação com universidades & 10 & 12,05 & 9 & 10,84 \\
\hline Total & $\mathbf{3 2}^{*}$ & $\mathbf{3 8 , 5 5}$ & $\mathbf{5 1}^{*}$ & $\mathbf{6 1 , 4 5}$ \\
\hline
\end{tabular}

Fonte: dados da pesquisa.

*A pergunta permite mais de uma alternativa de resposta.

No que tange as empresas não internacionalizadas há uma parcela considerável de empresas que são as principais responsáveis pela atividade de inovação. Contudo, percebe-se que predomina nas empresas internacionalizadas a busca por fontes externas para introdução de inovação, como cooperação com universidades, outras empresas e institutos.

Os dados corroboram com os achados da Pintec (IBGE, 2013) ao apontar que, nas empresas industriais brasileiras, os investimentos em fontes externas de inovação são superiores aos gastos nas atividades internas de P\&D.

A origem do capital controlador das empresas é apresentada na Tabela 9.

Tabela 9 - Origem do capital controlador da empresa

\begin{tabular}{lcccc}
\hline & \multicolumn{2}{c}{ Internacionalizada } & \multicolumn{2}{c}{ Não internacionalizada } \\
\hline Origem do capital controlador & Frequência & \% & Frequência & $\%$ \\
\hline Nacional & 11 & 21,6 & 33 & 64,7 \\
Estrangeira & 2 & 3,9 & 0 & 0,0 \\
Nacional e estrangeira & 2 & 3,9 & 3 & 5,9 \\
\hline Total & $\mathbf{1 5}$ & $\mathbf{2 9 , 4}$ & $\mathbf{3 6}$ & $\mathbf{7 0 , 6}$ \\
\hline
\end{tabular}

Fonte: dados da pesquisa.

A origem do capital controlador das empresas pesquisadas é prioritariamente nacional tanto em empresas internacionalizadas como não internacionalizadas.

Na Tabela 10, são apresentados dados referentes às certificações das empresas.

Tabela 102 - Certificações

\begin{tabular}{rccccc}
\hline & \multicolumn{2}{c}{ Internacionalizada } & \multicolumn{2}{c}{ Não internacionalizada } \\
\hline & Certificações & Frequência & \% & Frequência & \% \\
\hline $\operatorname{Sim}$ & 13 & 25,5 & 19 & 37,3 \\
Não & 2 & 3,9 & 17 & 33,3 \\
\hline Total & $\mathbf{1 5}$ & $\mathbf{2 9 , 4}$ & $\mathbf{3 6}$ & $\mathbf{7 0 , 6}$ \\
\hline
\end{tabular}

Fonte: dados da pesquisa.

Quase a totalidade das empresas internacionalizadas possui algum tipo de certificação, o que evidencia a busca por melhores padrões de trabalho por meio da adoção de parâmetros aceitos no âmbito internacional, tendo em vista que os organismos certificadores, em sua maioria, dispõem de diretrizes consolidadas e aceitas mundialmente.

A seguir, são apresentados os resultados da análise da postura estratégica para a inovação sustentável. 


\subsection{POSTURA ESTRATÉGICA PARA A INOVAÇÃO SUSTENTÁVEL}

Na Tabela 11, são apresentados os resultados referentes à postura estratégica para a inovação sustentável das empresas analisadas.

Tabela 31 - Postura estratégica para a inovação sustentável

\begin{tabular}{|c|c|c|}
\hline & Internacionalizadas & $\begin{array}{c}\text { Não } \\
\text { Internacionalizadas }\end{array}$ \\
\hline Postura estratégica para a inovação sustentável & Média & Média \\
\hline \multicolumn{3}{|l|}{ Pró-ativa em produto } \\
\hline $\begin{array}{l}\text { A sustentabilidade integrada de forma estratégica em seus } \\
\text { produtos e/ou serviços a fim de criar novos conceitos no } \\
\text { mercado. }\end{array}$ & 4,20 & 4,11 \\
\hline $\begin{array}{l}\text { Liderança no mercado a partir do lançamento de produtos } \\
\text { e/ou serviços sustentáveis visando a geração de vantagem } \\
\text { competitiva. }\end{array}$ & 3,80 & 3,81 \\
\hline \multicolumn{3}{|l|}{ Pró-ativa em processo } \\
\hline $\begin{array}{l}\text { Os objetivos da sustentabilidade integrada de forma } \\
\text { estratégica em seus processos empresariais. }\end{array}$ & 3,70 & 3,85 \\
\hline $\begin{array}{l}\text { Liderança no mercado por meio da introdução de novos } \\
\text { processos sustentáveis visando à geração de vantagem } \\
\text { competitiva. }\end{array}$ & 3,70 & 3,51 \\
\hline \multicolumn{3}{|l|}{ Acomodativa em produto } \\
\hline $\begin{array}{l}\text { A sustentabilidade integrada em alguns dos seus produtos } \\
\text { e/ou serviços visando exclusivamente atender aos requisitos } \\
\text { legais e/ou a pressões externas e reduzir custos. }\end{array}$ & 3,10 & 3,11 \\
\hline $\begin{array}{l}\text { Alguns novos produtos e/ou serviços desenvolvidos } \\
\text { considerando os critérios da sustentabilidade visando } \\
\text { exclusivamente atender aos requisitos legais e/ou a pressões } \\
\text { externas e reduzir custos. }\end{array}$ & 3,00 & 3,26 \\
\hline \multicolumn{3}{|l|}{ Acomodativa em processo } \\
\hline $\begin{array}{l}\text { A sustentabilidade integrada em alguns dos seus processos } \\
\text { visando exclusivamente atender aos requisitos legais e/ou a } \\
\text { pressões externas e reduzir custos. }\end{array}$ & 3,30 & 3,15 \\
\hline $\begin{array}{l}\text { Alguns novos processos desenvolvidos considerando os } \\
\text { objetivos da sustentabilidade visando exclusivamente atender } \\
\text { aos requisitos legais e/ou a pressões externas e reduzir custos. }\end{array}$ & 3,10 & 3,18 \\
\hline \multicolumn{3}{|l|}{ Defensiva em produto } \\
\hline $\begin{array}{l}\text { Pequenas melhorias em seus produtos e/ou serviços a fim de } \\
\text { integrar os objetivos da sustentabilidade visando } \\
\text { exclusivamente atender os requisitos legais e/ou a pressões } \\
\text { externas. }\end{array}$ & 3,20 & 3,30 \\
\hline $\begin{array}{l}\text { Pequenas melhorias em seus novos produtos e/ou serviços } \\
\text { considerando os critérios da sustentabilidade visando } \\
\text { exclusivamente atender os requisitos legais e/ou a pressões } \\
\text { externas. }\end{array}$ & 3,00 & 3,30 \\
\hline \multicolumn{3}{|l|}{ Defensiva em processo } \\
\hline $\begin{array}{l}\text { Pequenas melhorias em seus processos a fim de integrar os } \\
\text { objetivos da sustentabilidade visando exclusivamente } \\
\text { atender aos requisitos legais e/ou a pressões externas. }\end{array}$ & 3,40 & 3,44 \\
\hline $\begin{array}{l}\text { Pequenas melhorias em seus novos processos considerando } \\
\text { os critérios da sustentabilidade visando exclusivamente } \\
\text { atender aos requisitos legais e/ou a pressões externas. }\end{array}$ & 3,00 & 3,41 \\
\hline
\end{tabular}

Fonte: dados da pesquisa. 
No que tange a estratégia para a inovação sustentável pode-se perceber que no que se refere as empresas internacionalizadas a sustentabilidade integrada de forma estratégica em seus produtos e/ou serviços a fim de criar novos conceitos no mercado e Liderança no mercado por meio da introdução de novos processos sustentáveis visando à geração de vantagem competitiva possuem média superior quando comparadas às empresas não internacionalizadas. Tais variáveis integram a postura pró-ativa para a inovação sustentável. A estratégia pró-ativa, segundo Schaltegger, Lüdeke-Freund e Hansen (2012), integra os objetivos ambientais ou sociais na lógica central do negócio, visando a contribuir para o desenvolvimento sustentável da economia e da sociedade. A empresa, por meio da estratégia pró-ativa, busca atingir suas metas de sustentabilidade ao mesmo tempo em que almeja a liderança por meio do desempenho sustentável.

Além disso, as variáveis que integram a postura defensiva para a inovação sustentável possuem média superior nas empresas não internacionalizadas.

A partir do exposto os resultados sugerem que as empresas internacionalizadas possuem maior tendência a adotarem uma estratégia pró-ativa em prol da inovação sustentável corroborando com os estudos de Lopez-Valeiras, Gomez-Conde e Naranjo-Gil (2015) e Ada, Kazancoglu e Sagnak (2013) ao sugerirem que a gestão da inovação sustentável tem sido associada em alguns estudos com a atuação internacional das empresas, de modo que é fundamental estimular a inovação sustentável para ganhar acesso a mercados internacionais, sendo muitas vezes um requisito básico para melhorar os negócios internacionais.

\section{CONSIDERAÇÕES FINAIS}

O presente estudo teve como principal objetivo analisar a relação da postura estratégica para a inovação sustentável com o estágio de internacionalização de empresas industriais brasileiras.

Os resultados evidenciaram que, as empresas internacionalizadas possuem um tempo médio de existência superior, maior número de funcionários e maior receita operacional bruta quando comparadas às empresas não internacionalizadas, atuam principalmente nas indústrias de máquinas e equipamentos, tecnológica e química. Tanto as empresas internacionalizadas como as não internacionalizadas introduziram no mercado, nos últimos cinco anos, predominantemente, inovações em produto e em processo. No que se refere a responsabilidade principal pela atividade de inovação predomina nas empresas internacionalizadas a busca por fontes externas para introdução de inovação, como cooperação com universidades, outras empresas e institutos. A origem do capital controlador das empresas pesquisadas é prioritariamente nacional em ambos os grupos de empresas. E o fato de possuir uma certificação está presente na quase totalidade das empresas internacionalizadas.

No que tange a postura estratégica para a inovação sustentável os resultados permitem afirmar que há uma tendência por parte das empresas internacionalizadas adotarem uma postura pró-ativa em prol da inovação sustentável evidenciando que tais organizações precisam se antecipar às exigências legais e demandas do mercado a fim de buscarem a liderança e serem mais competitivas no mercado internacional.

A partir do exposto, é possível depreender que a gestão estratégica para a inovação sustentável e a internacionalização são temas que carecem de maiores estudos a fim de 
melhor entender tais relacionamentos.

Como principais contribuições da pesquisa, pode-se destacar o entendimento do comportamento de empresas industriais brasileiras em relação a inovação sustentável e a internacionalização, o que pode contribuir para a difusão de práticas que respondam a questões específicas do contexto de atuação das empresas.

O estudo apresentou, como principais limitações, o número de empresas pesquisadas e o baixo número de empresas com atuação internacional, tendo em vista que se obteve um retorno pouco representativo em relação à população pesquisada. Nesse sentido, as evidências encontradas não poderão ser extrapoladas para o universo de pesquisa considerado, restringindo-se apenas ao conjunto de empresas participantes da amostra.

Sugere-se que estudos futuros busquem ampliar a amostra a fim de aprofundar os resultados apresentados e permitir outras análises visando encontrar novas variáveis que expliquem o fenômeno estudado.

Não obstante as limitações do presente estudo, foi possível apresentar evidências do comportamento das empresas com relação à gestão estratégica para a inovação sustentável e a internacionalização identificando elementos importantes para o desenvolvimento dessa área de conhecimento.

\section{REFERÊNCIAS}

AGUILERA-CARACUEL, J.; ORTIZ-DE-MANDOJANA, N. Green Innovation and Financial Performance: An Institutional Approach. Organization \& Environment, v. 26, n. 4, p. 365385, dez. 2013. DOI: 10.1177/1086026613507931.

AMIT, R.; ZOTT, C. Value creation in E-business. Strategic Management Journal, v. 22, n.6-7, p. 493-520. 2001. DOI: 10.1002/smj.187.

BelTRAMELLO, A.; HAIE-FAYLE, L.; PILAT, D. Why New Business Models Matter for Green Growth. OECD Green Growth Papers. OECD Publishing, Paris, fev. 2013. DOI: $10.1787 / 5 k 97 g k 40 v 3 l n-e m$.

BOCKEN, N. M. P.; SHORT, S.W.; RANA, P.; EVANS, S.. A literature and practice review to develop sustainable business model archetypes. Journal of Cleaner Production, Oxford, v. 65, p. 42-56, fev. 2014. DOI: https://doi.org/10.1016/j.jclepro.2013.11.039.

BOONS, F.A.A. Creating Ecological Value. An Evolutionary Approach to Business Strategies and the Natural Environment. Elgar, Cheltenham, 2009.

BOONS, F.; LÜDEKE-FREUND, F. Business models for sustainable innovation: state-of-the-art and steps towards a research agenda. Journal of Cleaner Production, Oxford, v. 45, p.9-19, abr. 2013. DOI: 10.1016/j.jclepro.2012.07.007.

BOONS, F.; MONTALVO, C.; QUIST, J.; WAGNER, M. Sustainable innovation, business models and economic performance: an overview. Journal of Cleaner Production, Oxford, v. 45, p. 18, 2013. DOI: http://dx.doi.org/10.1016/j.jclepro.2012.08.013.

BROWN, H. S.; DE JONG, M.; LEVY, D. L. Building institutions based on information 
disclosure: lessons from GRI's sustainability reporting. Journal of Cleaner Production, Oxford, v. 17, n. 6, p. 571-580, abr. 2009. DOI: 10.1016/j.jclepro.2008.12.009.

CHESBROUGH, H.; ROSENBLOOM, R. S. The role of the business model in capturing value from innovation: evidence from Xerox Corporation's technology spin-off companies. Industrial and Corporate Change, v. 11, n. 3, p. 529-555, jun. 2002. DOI: $10.1093 / \mathrm{icc} / 11.3 .529$.

DAFT, R. L.; MARCIC, D. Understanding Management. Versailles: Thomson - South-Western, 2004.

EIRIZ, V.; FARIA, A.; BARBOSA, N. Firm growth and innovation: Towards a typology of innovation strategy. Innovation: Management, Policy \& Practice, Maleny, v. 15, n. 1, p. $97-$ 111, mar. 2013. DOI: 10.5172/impp.2013.15.1.97.

GLOBAL REPORTING INITIATIVE - GRI. 2006. Diretrizes para relatório de sustentabilidade. Disponível em < http://www.globalreporting.org>. Acesso em 15 outubro de 2010.

GUNDAY, G.; ULUSOY, G.; KILIC, K.; ALPKAN, L. Effects of innovation types on firm performance. International Journal Production Economics, v. 133, p. 662-676, jan. 2011. DOI: 10.1016/j.ijpe.2011.05.014.

INSTITUTO BRASILEIRO DE GEOGRAFIA E ESTATÍSTICA - IBGE. Pesquisa de Inovação - 2011 (Pintec). Rio de Janeiro: 2013.

KIRON, D.; KRUSCHWITZ, N.; REEVES, M.; GOH, E. The Benefits of Sustainability-Driven Innovation. MIT Sloan Management Review, Cambridge, v. 54, n.2, p. 69-73, dez. 2013 a. DOI: 10.1002/9781119204084.ch15.

KIRON, D.; KRUSCHWITZ, N.; REEVES, M.; HAANAES, K.; GOH, E. The Innovation Bottom Line. MIT Sloan Management Review. Research Report, MIT Sloan Management Review and The Boston Consulting Group, Cambridge, p. 1-22, 2013b.

LACY, P.; COOPER, T.; HAYWARD, R.; NEUBERGER, L. A new era of sustainability:

CEO reflections on progress to date, challenges ahead and the impact of the journey toward a

sustainable economy. UN Global Compact - Accenture Sustainability Services: 2010.

LEVY, D. L.; SZEJNWALD, B. H.; DE JONG, M. The Contested politics of corporate governance the case of the Global Reporting Initiative. Business \& Society, Chicago, v. 49, 1, p. 88-115, mar. 2010. DOI: http://dx.doi.org/10.1177/0007650309345420.

LOPEZ-VALEIRAS, E.; GOMEZ-CONDE, J.; NARANJO-GIL, D. Sustainable Innovation, Management Accounting and Control Systems, and International Performance. Sustainability, Basel, v.7, n.3, p. 3479-3492, mar. 2015.

DOI:10.3390/su7033479 
MARIMON, F.; ALONSO-ALMEIDA, M, D. M.; RODRÍGUEZ, M. D. P.; ALEJANDRO, K. A. C. The worldwide diffusion of the global reporting initiative: what is the point? Journal of Cleaner Production, Oxford, v. 33, p. 132-144, set. 2012. DOI: 10.1016/j.jclepro.2012.04.017.

NEELY, A.; ADAMS, C.; KENNERLEY, M. The performance prism: the scorecard for measuring and managing business success. London: Prentice Hall, 2002.

OCDE - ORGANIZAÇÃO PARA COOPERAÇÃO ECONÔMICA E DESENVOLVIMENTO. Manual de Oslo: diretrizes para coleta e interpretação de dados sobre inovação. 3 ed. Rio de Janeiro: FINEP, 2005.

PRADO-LORENZO, J. M.; GALLEGO-ALVAREZ, I.; GARCIA-SANCHEZ, I. M. Stakeholder engagement and corporate social responsibility reporting: the ownership structure effect. Corporate Social Responsibility and Environmental Management, Sydney, v. 16, p. 94-107, fev. 2009. DOI: https://doi.org/10.1002/csr.189.

RASCHE, A. Toward a model to compare and analyze accountability standards - the case of the UN global compact. Corporate Social Responsibility and Environmental Management, Sydney, v. 16, p. 192-205, jul. 2009. DOI: 10.1002/csr.202.

SCHALTEGGER, S.; LÜDEKE-FREUND, F.; HANSEN, E. G. Business cases for sustainability: the role of business model innovation for corporate sustainability. International Journal of Innovation and Sustainable Development, Genebra, v. 6, n.2, jul. 2012. DOI: 10.1504/IJISD.2012.046944.

SEEBODE, D.; JEANRENAUD, S.; BESSANT, J. Managing innovation for sustainability. R\&D Management, Oxford, v. 42, n. 3, p. 195-206, jun. 2012. DOI: 10.1111/j.14679310.2012.00678.x.

SKOULOUDIS, A.; EVANGELINOS, K.; KOURMOUSIS, F. Development of an evaluation methodology for triple bottom line reports using international standards on reporting. Environmental Management, Nova lorque, v. 44, p. 298-311, jul. 2009. DOI: $10.1007 /$ s00267-009-9305-9.

SZEKELY, F.; STREBEL, H. Strategic innovation for sustainability. IMD - International Institute for Management Development: 2012. Disponível em <http://www.imd.org>. Acesso em dezembro de 2013.

TARAN, Y. Rethinking it all: Overcoming obstacles to business model innovation. PhD thesis, Center for Industrial Production, Aalborg University, Aalborg, Denmark, 2011.

TARAN, Y.; BOER, H.; LINDGREN, P. A Business Model Innovation Typology. Decision Sciences, v.46, n.2, p.301-331, abr. 2015. DOI: 10.1111/deci.12128.

TEECE, D. J. Business Models, Business Strategy and Innovation. Long Range Planning, v. 43, n. 2-3, p. 172-194, abr.-jun. 2010. DOI: https://doi.org/10.1016/j.Irp.2009.07.003. 
TSANG, S.; WELFORD, R., BROWN, M. Reporting on community investment. Corporate Social Responsibility and Environmental Management, Sydney, v. 16, p. 123-136, nov. 2009. DOI: https://doi.org/10.1002/csr.178.

WAGNER, M. The role of corporate sustainability performance for economic performance: A firm-level analysis of moderation effects. Ecological Economics, v.69, n.7, p.1553-1560, mai. 2010. DOI: 10.1016/j.ecolecon.2010.02.017. 